This item was submitted to Loughborough's Research Repository by the author.

Items in Figshare are protected by copyright, with all rights reserved, unless otherwise indicated.

\title{
Optimal structure of a Smart DC micro-grid for a cluster of zero net energy buildings
}

PLEASE CITE THE PUBLISHED VERSION

http://dx.doi.org/10.1109/ENERGYCON.2016.7514132

PUBLISHER

(C) IEEE

VERSION

AM (Accepted Manuscript)

LICENCE

CC BY-NC-ND 4.0

REPOSITORY RECORD

Gonzalez-Longatt, Francisco M., Bharat Singh Rajpurohit, and Sri Niwas Singh. 2019. "Optimal Structure of a Smart DC Micro-grid for a Cluster of Zero Net Energy Buildings”. figshare. https://hdl.handle.net/2134/23018. 


\section{Optimal Structure of a Smart DC micro-grid for a Cluster of Zero Net Energy Buildings}

\author{
Francisco Gonzalez-Longatt \\ Loughborough University \\ School of Electric, Electronic and \\ Systems Engineering \\ Loughborough, United Kingdom \\ fglongatt@fglongatt.org
}

\author{
Bharat Singh Rajpurohit \\ School of Electrical \& Computer Sc. \\ Indian Institute of Technology Mandi \\ Himachal Pradesh \\ bsr@iitmandi.ac.in
}

\author{
Sri Niwas Singh \\ Department of Electrical Engineering \\ Indian Institute of Technology \\ Kanpur, Kanpur, India \\ snsingh@iitk.ac.in
}

\begin{abstract}
A decarbonized society involves people living and working in low-energy and low-emission buildings. A smart multi-Terminal DC micro-grids interconnecting several autonomous zero-net energy buildings (ZNEBs) allow the transition to a decarbonized economy, however, involves several challenges. This paper evaluates the problem of an optimal topology for a cluster of several ZNEBs and it takes several advantages related to the holistic operation and planning. A high-resolution electricity demand model is used together with several scenarios of stochasticity (weather, human behaviour, etc.) in order to create several credible scenarios of electricity demand at each ZNEB and then solve the constrained optimization problem of two network topologies for the cluster of interacting ZNEB. This paper has demonstrated the appropriate performance of the proposed approach using a verys simple, demonstrative/illustrative, example, a cluster of three DC-Houses.
\end{abstract}

Index Terms-- DC-grids, electrical energy storage, micro-grids, optimization, renewable energy sources.

\section{INTRODUCTION}

Challenges of future electricity networks are expected to growth and threatening to global security and prosperity. A general consensus about them includes [1]: (i) climate change, (ii) system security and (iii) economy globalization. The situation is complex because resources across the world are becoming scarce and the need for sustainable growth is increasingly important [1]. As a part of a national climate change strategy, governments around the world are propitiating thoughtful efforts toward to become sustainable and decarbonised economies. The evolution of a decarbonised economy comprises three main aspects [1]: (i) developing energy efficiency measures, (ii) developing renewable energy capabilities and (iii) to deal with adaptation needs arising due to climate change. Energy efficiency is one of the key factors on migrating to a decarbonised economy, i.e. moving to a lowcarbon society. European Union (EU) is expecting to use around 30\% less energy in 2050 than in 2005. A decarbonised society involves people living and working in low-energy, low-emission buildings, including intelligent heating and cooling systems, and other low energy and high-efficiency energy services (transportation, etc.).

There is a huge prospect to optimise the energy use of both domestic and business customers. Households and businesses would take advantage of more secure and efficient energy including two important benefits: reducing energy bills while at the same time, delivering a more sustainable society. There are several initiatives around the world in order to develop very low energy buildings [2-7].

EU is enforcing the development of Nearly Zero-Energy Buildings, according to article 9 of the Directive 2010/31/EU [8], "Member States shall ensure that by 31 December 2020 all new buildings are nearly zero-energy buildings; and after 31 December 2018, new buildings occupied and owned by public authorities are nearly zero-energy buildings" [8]. In addition, that EU directive defines the Nearly Zero-Energy Buildings as "a building that has a very high energy performance. The nearly zero or very low amount of energy required should be covered to a very significant extent by energy from renewable sources, including energy from renewable sources produced on-site or nearby" [8]. UK was the first country in the world to create a national legal framework for tackling climate change, the Climate Change Act [9] was introduced in 2008, creating a long-term legallybinding framework for coping with the climate change. It sets a target of reducing the net UK carbon account for all six Kyoto greenhouse gases by $80 \%$ compared to 1990 levels by 2050 , with a reduction of at least $34 \%$ by 2020 . In addition, UK is one of the first countries in the world to have committed to research and development on Nearly Zero-Energy Buildings.

In December 2006, the UK's government committed that from 2016 all new homes would be 'zero carbon' and introduced the Code for Sustainable Homes (CSM) [10], a code against which the sustainability of new homes could be rated. This commitment was affirmed in the Building a Greener Future: Policy Statement in 2007 which proposed a progressive tightening of the building regulations to achieve the 2016 goal, first by $25 \%$ in 2010 and then by $44 \%$ in 2013 .

This work was supported in part by British Council under the UKIERI, under grant DST/INT/UK/P-61/2014. 
However, the CSM was discontinued as a separate code on 27 March 2015 and the UK government proposed to consolidate housing regulations and standards, incorporating the $\mathrm{CSH}$ standards into Part L of the Building Regulations.

This paper evaluates the problem of an optimal topology for a cluster of several ZNEBs takes several advantages related to the holistic operation and planning. The highresolution energy demand model is used together with several scenarios of stochasticity (weather, human behaviour, etc.) in order to create several credible scenarios of electricity demand at each ZNEBs and then solve the constrained optimization problem of a network topology for the cluster of interacting ZNEBs. This paper has demonstrated the appropriate performance of the proposed approach using a demonstrative/illustrative example, a cluster of 3 DC-Houses. The paper is organized as follows: Section II presents all modelling aspects of a DC-House; Section III explains the optimization problem and Section IV simulations and results on a cluster of three DC-houses. Section V concludes.

\section{Model ARCHITECTURE OF NANO-GRID: DC-HousE}

Energy use in the DC-home is a major source electricity consumption and is highly dependent on the activities of the residents [10, 11]. As a consequence, the appropriate simulation of the electricity demand inside a Nano-grid requires a model capable of reflects dependent upon the activities of the occupants and their associated use of electrical appliances. In this paper a high-resolution model of domestic electricity use that is based on a combination of patterns of active occupancy (i.e. when people are at home and awake), and daily activity profiles that characterize how people spend their time performing certain activities [12].

The original idea, work and development of the highresolution model of domestic electric used was originally introduced by I. Richardson et al. [13], and several improvement has been developed during years [14-16]. The construction and validation of this model are presented in earlier published work by the I Richardson. In this paper, the high-resolution model has been modified and improved including wind power generation and it is been used to include battery energy storage.

The outline structure of the Nano-grid model is presented in Figure 1.

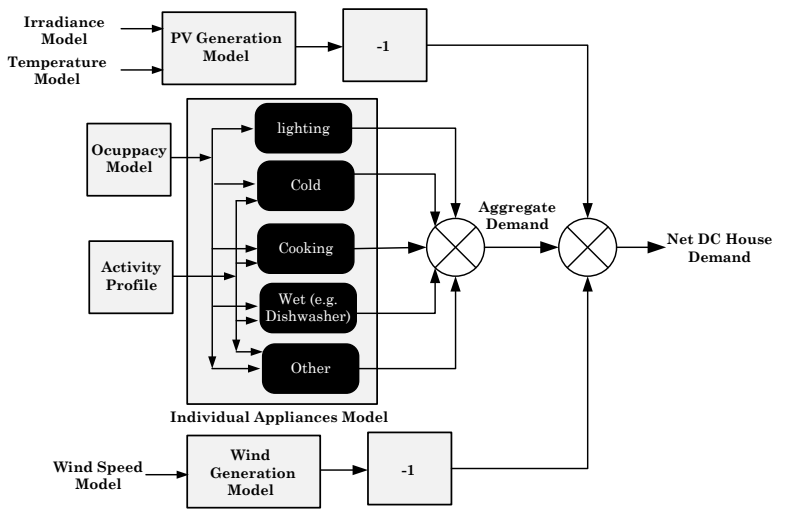

Figure 1. Outline Structure of the High-Resolution Model of Nano-grid.
The outdoor irradiance, outdoor temperature, and wind speed are used as inputs to the model. The core of this model includes the simulation of the major types of domestic electrical appliances, including cold, cooking, and wet categories.

The active occupancy as a main component of the model in order to introduce the social behaviour influencing the domestic energy demand. The following subsection defines the main subcomponents of the model.

\section{A. Occupancy model}

The model of active domestic occupancy defines the numbers of occupants that are within the DC-house, and this is a key element because it is identified to be a main driver of electricity. The model used in this paper is based on [13]. The model creates synthetic occupancy data based on a first order Markov-Chain, this is a well-proven and used technique. The model requires the deduction of a Transition Probability Matrix (TPM), and this is calculated from a source data; that details the probability of a transition from one level of active occupancy to another, at each time step throughout a day. For simplicity, this paper uses data obtained from the Time Use Survey (TUS) [13], this data has been used in several publications with extremely good results.

\section{B. Individual Appliances Model}

Model of individual appliances is used to simulate the use of all the major types of domestic electrical appliances, including (i) cold, (ii) cooking, and (iii) wet categories. The model uses individual appliances demand based upon activity profiles, constructed from time use data, which represents how people spend their time. Finally, the model sums the electrical demand of each appliance at a given time providing the aggregate demand of the DC-house. An implementation of the individual appliance model is available in the form of Microsoft Excel Sheet at https://dspace.lboro.ac.uk/2134/8774, it includes activity profiles and other relevant data. The authors of this paper have created an MATLAB implementation of this code including and Microsoft Excel interface.

\section{PV Generation Model}

The photovoltaic generation model is based on two components: (i) irradiance model and (ii) $P V$ production model.

\section{1) Irradiance Model}

The level of outdoor irradiance at calculated as the produce of two main aspects (see Figure 2):

- Model of irradiance at the surface during 'clear sky' conditions. The clear sky irradiance, at a specific point (longitude and latitude), can be approximated by the calculation of the solar position. In this paper, Haurwitz clear sky model for global horizontal irradiance (GHI) as presented [17].

- Model of irradiance attenuation. This attenuation is a consequence of the changing weather conditions; it is particularly relevant in the case of clouds passing overhead throughout the day. Detailed modelling of 
patching clouds moving across the sky using detailed atmospheric model requires complex processes. The data of the attenuation caused by cloud can be approximated using synthetic data. A simple way to model irradiance attenuation is using a clearness index. Synthetic data of clearness index is created using a first order MarkovChain; this is a well-proven and used technique. The Transition Probability Matrix (TPM) used in this paper is based on [16].

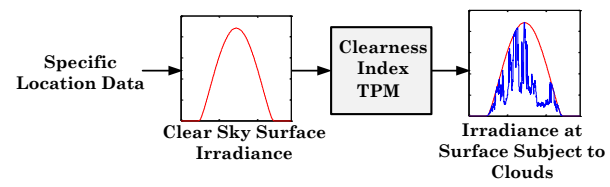

Figure 2. Irradiance Model.

\section{2) PV production Model}

A simple conversion model is used for the PV production chain. The model requires the incident radiation at the PV panel location; it uses the surface area of the panel array, and a global general efficiency to calculate the generated power (see Figure 3). This approach has been used in the literature with extremely good results.

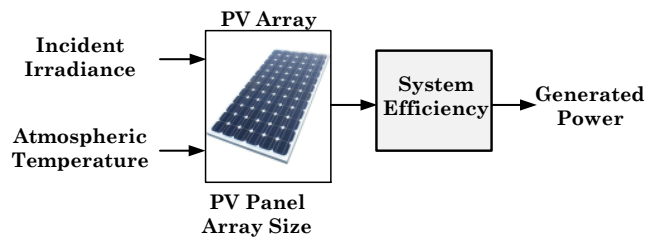

Figure 3. PV Production Model.

\section{Wind Turbine Model}

A simple energy conversion model is used for the wind turbine (see Figure 4). The wind turbine generator is modelled such that the electrical power is the product of a system efficiency and the wind power incident on turbine blade $\left(P_{\text {wind }}\right)$ is:

$$
P_{\text {wind }}=\frac{1}{2} C_{p} \rho \pi r^{2} V_{w}^{3}
$$

where, $C_{p}$ is a power coefficient $\rho$ is the air density $\left(\mathrm{kg} / \mathrm{m}^{3}\right), r$ is the blade length $(\mathrm{m})$ and $V_{w}$ is the wind speed.

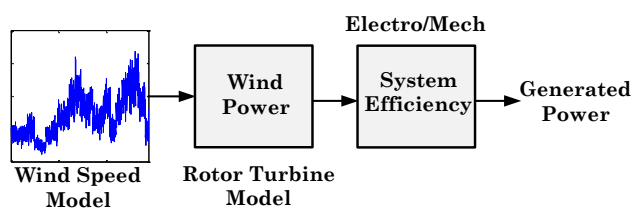

Figure 4. Wind Turbine Model.

\section{OPTIMIZATION MODEL}

Optimal power flow (OPF) is a common tool used for the optimization of the steady-state operation of a given $\mathrm{AC}$ power system network. The idea of an OPF algorithm is to find a set of values of the network parameters which will optimize one (or more) the system's functionalities [18], i.e. system power losses, total generation cost, operational limits, or system security. The steady-state behaviour of a multiterminal DC system (MTDC) system can be described by a set of nonlinear set of the algebraic equations [19]:

$$
\mathbf{G}(\mathbf{X}, \mathbf{Y})=\mathbf{0}
$$

where $\mathbf{G}$ is the set of algebraic equations define the power balance at network buses as shown in (5), and $\mathbf{X}$ is state vector and $\mathbf{Y}$ is the vector of the independent variable. The state vector contains the state variables describing the state of the MTDC system, it contains dependent variables [20]. DC voltages can be dependent or independent variables depending on the voltage control used. Slack node and other voltage-type nodes provide known or independent variables contained in $\mathbf{Y}$.

OPF is formulated mathematically as a general constrained optimization problem where a set of constraints are taking into account. The most basic and general OPF formulation is based on a problem of minimization without inequality constraints as $[20,21]$ :

$$
\min f(\mathbf{X}, \mathbf{Y})
$$

Subject to:

$$
\mathbf{G}(\mathbf{X}, \mathbf{Y})=0
$$

where $f(\mathbf{X}, \mathbf{Y})$ is the function to be optimized.

\section{A. Definition of Objective Function}

The problem of optimizing the performance of a MTDC system is formulated as a general optimization problem. It is required to state from which point of view the performance of the system will be optimized. In the classical problem of OPF, the objective function is "to minimize the overall generating cost". Most of the published OPF algorithms seek to optimize only one objective function, however, many other objective functions are possible [22]: minimize changes in controls, minimize system losses, maximize security, etc. After a literature review, the number of published paper contributed to the OPF multi-objective problem is small [22], and the favourite combined objectives may include, generating cost, environmental variables and security. In terms of OPF, the most used objective function minimizes the system losses as is applied on [23], [18], etc. An energy/power management system is expected of being part of smart MTDC, it controls and monitors the operation of the MTDC involving one or several DC-Houses, as consequence minimize the system losses is expected to be one of the set of priorities during the normal and optimal steady-state operation [20].

In this paper, power losses $\left(P_{\text {losses }}\right)$ are located on the DC transmission system and it is assumed to be the Joule heating or ohmic heating in the cables. Under the previous assumption, the total losses in a MTDC system can be written as $[20,21]$ :

$$
f(\mathbf{X}, \mathbf{Y})=P_{\text {losses }}=\sum_{i=1}^{n_{d c}} P_{d c, i}
$$


where $P_{d c, i}$ are the elements in $\mathbf{P}_{\mathbf{d c}}$ calculated in terms of the nodal voltages using (5).

\section{B. Definition of Constraints}

The OPF in MTDC is a mathematical optimization problem, typically called constraint optimization. In this process, the objective function, $f(\mathbf{X}, \mathbf{Y})$, is optimized with respect to some variables in the presence of constraints on those variables [21]. The constraints divide the searching space into two domains, the feasible domain where the constraints are satisfied, and the infeasible domain where at least one of the constraints is violated [20]. In general terms, the OPF problem may include several special forms for constraints [20]: nonlinear constraints, bound constraints, linear inequality constraints, and linear equality constraints. A description of the constraints used in this paper is presented in the next sub-sections.

\section{1) Bound constraints}

Lower $\left(\mathbf{X}_{\min }\right)$ and upper $\left(\mathbf{X}_{\max }\right)$ bounds limit the components of the solution $\mathbf{X}$. Bound constraints are written in the form of:

$$
\mathbf{X}_{\min }<\mathbf{X}<\mathbf{X}_{\text {max }}
$$

DC/DC converters are used to control DC voltage inside MTDC. Those power converters, usually use IGBTs as commutation devices which are extremely sensible and have very low capacity to cope with voltages changes [24]. DC overvoltage, which may stress the commutation devices and extremely low under-voltages, can cause destructive overcurrent on the IGBT $[20,24]$. Therefore, there are limits with regard to steady state voltage ranges at the converter stations. In this paper, the $i$-th node DC-voltage at station converters $\left(U_{d c, i}\right)$ are written as bound constraints based on operational limits:

$$
U_{\min }<U_{d c, i}<U_{\max }
$$

where $U_{\min }$ and $U_{\max }$ represent the minimum and maximum allowed voltage. The use of bound constraints allow met technical operational limits but at the same time, there is a mathematical advantage because allow obtaining faster and more reliable solutions because the searching space is reduced [19].

\section{2) Nonlinear equality constraints}

Nonlinear inequality constraints have the form $\mathbf{G}(\mathbf{X}, \mathbf{Y})=$ $\mathbf{0}$, where $\mathbf{G}$ is a vector of constraints, one component for each constraint. The mathematical formulation of the OPF includes a set of nonlinear equality constraints [19]. The constraints represent the power balance at each node or power flow equations. In most practical problems the minimum is found at the boundary between the feasible and infeasible domains, that is at a point where $\mathbf{G}(\mathbf{X}, \mathbf{Y})=\mathbf{0}$.

\section{3) Linear inequality constraints}

Linear inequalities constraints have a form as:

$$
\mathbf{A}_{\text {ieq }} \mathbf{X}<\mathbf{B}_{\text {ieq }}
$$

where $\mathbf{A}_{\text {ieq }}$ is an $n$-by- $m$ matrix, which represents $m$ constraints for an $n$-dimensional vector $\mathbf{X}$. $\mathbf{B}_{\text {ieq }}$ is $m$ dimensional. In most optimization problems, the inequality constraints prescribe limit the components of the solution $\mathbf{X}$.
There is a very strict current limitation on the DC/DC converter used in MTDC systems. The power-converter commutation devices, usually IGBTs, have very little, if any, over current capacity. The VSC control system will make sure that the converter valves maximum current are not exceeded. Linear inequalities constraints is used in the OPF problem of MTDC to represent the maximum current limit in converters [20]:

$$
\mathbf{I}_{\text {conv }}<\mathbf{I}_{\text {conv }}^{\text {max }}
$$

where $\mathbf{I}_{\text {conv }}^{\max }$ represents a vector containing the maximum loading current allow in each converter station. Using the nodal analysis, the nodal current can be transformed into a set of linear inequalities constraints as follow:

$$
\mathbf{I}_{\text {conv }}=\mathbf{Y}_{\mathrm{dc}} \mathbf{U}_{\mathrm{dc}}<\mathbf{I}_{\text {conv }}^{\text {max }}
$$

where $\mathbf{A}_{\mathbf{i e q}}=\mathbf{Y}_{\mathbf{d c}}, \mathbf{X}=\mathbf{U}_{\mathbf{d c}}$ and $\mathbf{B}_{\mathbf{i e q}}$ as defined above.

4) Linear equality constraints

Linear equality constraints have a form as [20]:

$$
\mathbf{A}_{\text {eq }} \mathbf{X}=\mathbf{B}_{\text {eq }}
$$

where $\mathbf{A}_{\text {eq }}$ is an $n$-by- $m$ matrix, which represents $m$ ' constraints for an $n$-dimensional vector $\mathbf{X} . \mathbf{B}_{\text {eq }}$ is $m$ dimensional.

\section{SimUlation AND RESUlTS}

This section is dedicated to presents results of the optimal steady-state operation of a cluster of three ZNEB, considering two topologies for the high power layer: delta and star. The high-resolution (1-minute) demand of each DC-House is created considering a set of a number of residents, weekday and weekend days.

For demonstrative purposes, a cluster of three ZNEBs, nano-grids, is considered: DC-House 1, DCHouse2, and DCHouse3. The number of residents is assumed different in those houses, and the occupancy pattern is created considering is created considering the occupancy model presented in previous sections. Figure 5 and Figure 6 shows the simulated high-resolution active occupancy and electricity demand pattern for the three DC-houses considered (blue colour represents weekdays 'wd', and red colour weekends -'we'). Using the irradiance model presented in the previous section, three global irradiances are simulated.

The simulated global irradiance pattern, including the cloud attenuation (see Figure 7), is used to simulate the photovoltaic generation installed at each DC-House.

A synthetic wind-speed time series is created and then is introduced to the wind turbine model as presented in the previous section. A 2,000-Watt wind turbine is installed in DC-Housel and Figure 8 shows the simulated wind power production.

Let us consider a cluster of three DC-Houses, the graph theory allows knowing, there are only two possible ways to connect three nodes, using three branches. Consequently, two simple topologies are candidates for optimal power connection of three DC-houses: Case I: Delta connection and Case II: Star connection (see Figure 9). 
This is a very basic example; however, it is illustrative about the optimal topology for the optimal steady-state operation of a cluster of ZNEBs.

Bipolar DC system is used on the MTDC, and the cable resistance is representative of medium voltage DC cables commercially available in the market. Resistance values have been assumed equivalent between Case I and Case II.

A MATLAB ${ }^{\circledR}$ R2014a (version 8.3.0.532 64-bit) program (m-file) has been developed in order to calculate the optimal steady-state operation of a cluster of three ZNEB. All simulations are performed using a PC based on Intel ${ }^{\circledR}$, Core $^{\mathrm{TM}}$ i7 CPU 2.5GHz, 16 GB RAM with Windows 8.1 64-bit operating system.



(a) DC-House 1: 2

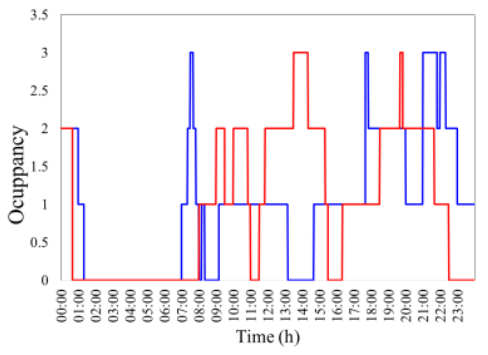

(b) DC-House2: 3

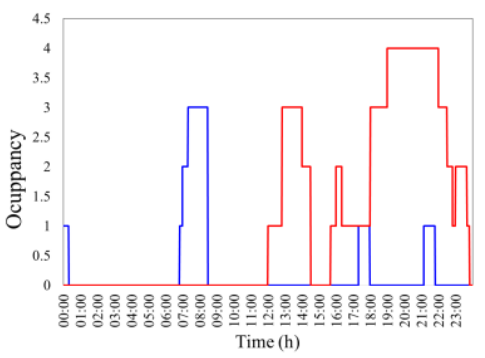

(c) DC-House 3: 4

Figure 5. Simulated Active Occupancy Pattern. Number of Residents presented in parenthesis.

Figure 10 shows the simulation results of DC-voltage in the three terminal nodes $\left(U_{d c i}\right)$ of the high power layer. The voltage profiles show an important dependence on the generation/demand balance in the MTDC. DC-Homel has installed a wind turbine and a battery energy storage; therefore, the lowest voltage variations are reasonably located at $U_{d c 1}$. Simulation results demonstrate a lower voltage profile in the MTDC during weekends ('we'); this is a just consequence of the larger power consumption because larger occupancy. Simulations results indicate Case II presents lower voltage exclusion compared with the Case I.

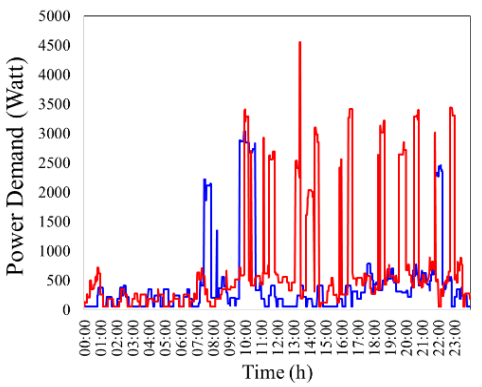

(a) DC-House1: (436.94/711.60)

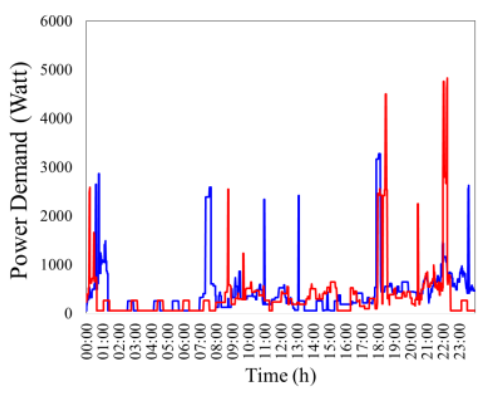

(b) DC-House2: (416.24/365.44)

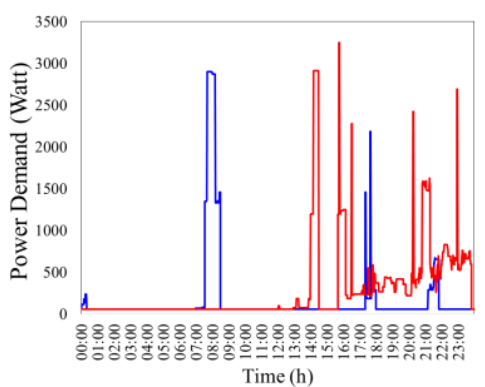

(c) DC-House3: (165.19/290.32)

Figure 6. Simulated Electricity Demand Pattern. Values presented in parenthesis represent averages values of weekday and weekend ('wd'/'we').

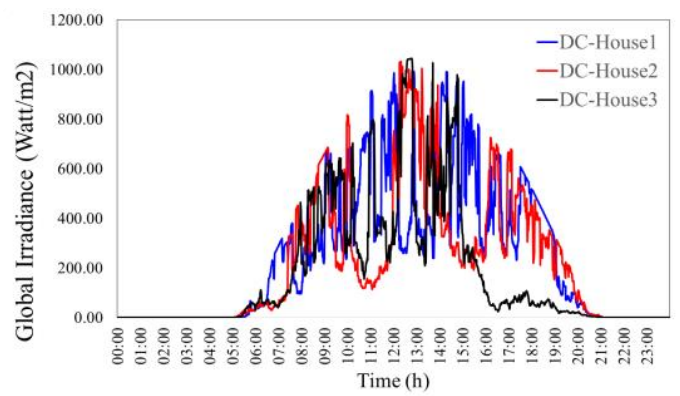

Figure 7. Simulated Global irradiance considering attenuation due to clouds.

In this paper, the optimal topology is defined based on minimal losses. Figure 11 shows the total losses in the MTDC system, using a 1-minute resolution, considering load profiles for weekday and weekends and assuming two topological configurations (Case I and Case II). As expected, maximum losses are related to weekend days, when the demand is increased by the larger activity of home residents, also, simulation results demonstrate the larger losses exclusions in Case II. Regarding, average losses during 24 hours period, Case I exhibit the lower losses for the Scenarios considered. Finally, based on simulations results, the Delta topology 
exhibit the best performance in terms of power losses under considered scenarios.

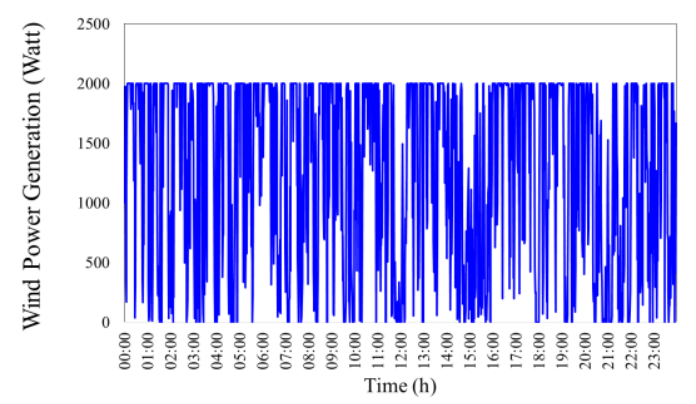

Figure 8. Simulated Global irradiance with cloud attenuation.

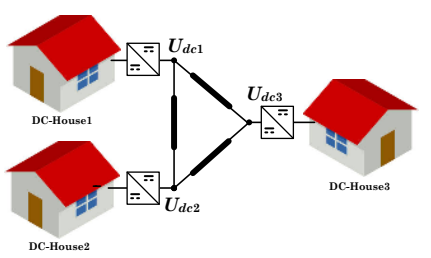

(a) Case I: Delta connection

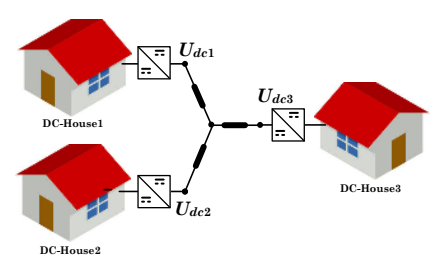

(b) Case II: Star connection.
Figure 9. Simulated Topologies Scenarios of High Power Layer -MTDC. $R_{13}$ $=0.045, R_{23}=0.052, R_{12}=0.073$ per unit.

\section{CONCLUSIONS}

The key factors on the transition to a decarbonised economy are energy efficiency, renewable energy and economic prosperity. Development of a smart multi-terminal DC $\mu$-grids for autonomous zero-net energy buildings, which allow enhancing the benefits of several already known concepts into a novel concept allowing the transition to a decarbonized economy. The Smart MTDC $\mu$ g concept is a key component on the development of a smart multi-terminal DC $\mu$-grids for autonomous ZNEB. It provides several advantages: (i) Integrated design and operations planning considering non-dispatchable RES with uncorrelated primary source and constrained distributed energy storage systems; (ii) Real-time energy balance considering $100 \%$ non-dispatchable RES (wind and solar power); (iii) Recovery energy consumption of electricity storage systems after a major contingency; (iv) Risk of blackout and large outages during adverse weather conditions; (v) Other emerging challenges related to technology and legal framework.

This paper introduces all relevant concepts of smart DC micro-grid for a cluster of $\mathrm{ZNEB}$ and the design requirements in order to allow the near zero energy goal over the timehorizon. The second part of the paper is dedicated to defining the topology optimization problem where the design requirement are used as constraints. The pattern of electricity use in an individual domestic ZNEB is highly dependent upon the activities of the occupants and their associated use of electrical appliances. A high-resolution model of domestic electricity use is presented in this paper together with the combination of patterns of active occupancy (i.e. when people are at home and awake), and daily activity profiles that characterise how people spend their time performing certain activities. The high-resolution energy demand model is used together with several scenarios of stochasticity (weather, human behaviour, etc.) in order to create several credible scenarios of electricity demand at each ZNEB and then solve the constrained optimization problem of a network topology for the cluster of interacting ZNEB. This paper has demonstrated the appropriate performance of the proposed approach using a demonstrative/illustrative example, a cluster of 3 DC-Houses

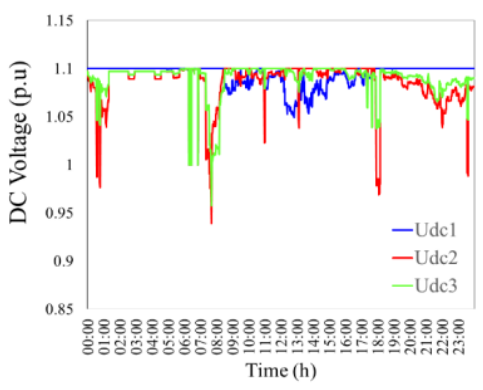

(a) Case I: Weekdays ('wd')

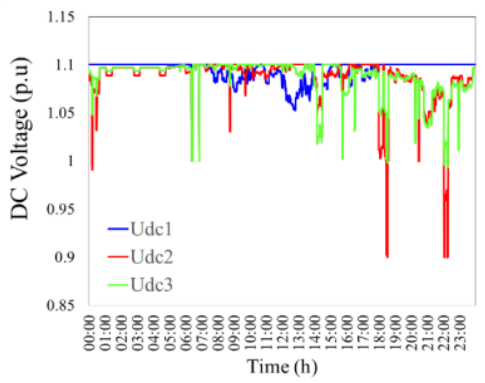

(b) Case I: Weekend ('we')

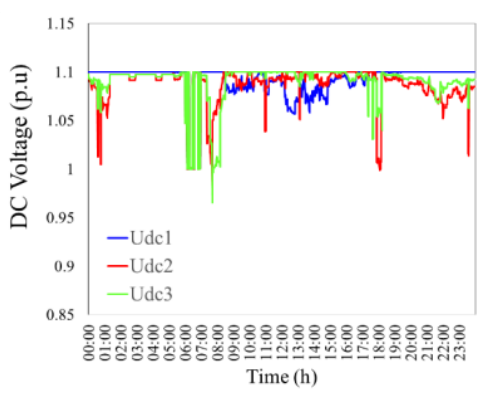

(c) Case II: Weekdays ('wd')

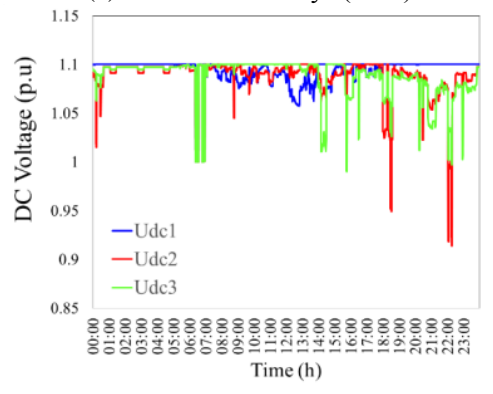

(d) Case II: Weekend ('we')

Figure 10. Simulated Results: DC-Voltages (p.u). 


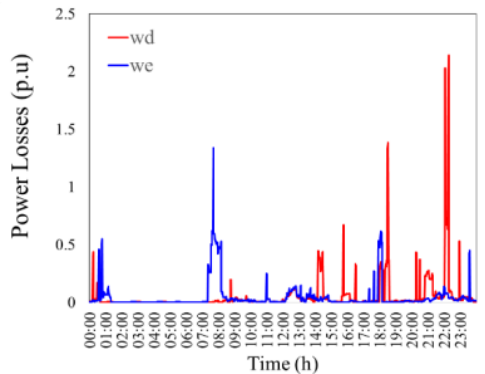

(a) Case I

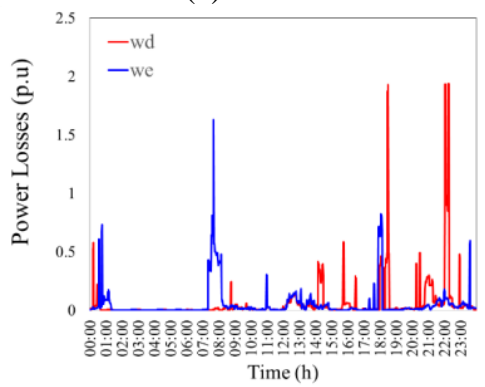

(b) Case II

Figure 11. Simulated Results: Power Losses (p.u).

\section{REFERENCES}

[1] F. Gonzalez-Longatt, "Frequency Control and Inertial Response Schemes for the Future Power Networks," in Large Scale Renewable Power Generation, J. Hossain and A. Mahmud, Eds., ed: Springer Singapore, 2014, pp. 193-231.

[2] COOPERaTE. (2013). COOPERaTE: Control and Optimization for Energy Positive Neighbourhoods. Available: http://www.cooperatefp7.eu/index.php/home.html

[3] DIMMER. (2013). DIMMER: District Information Modeling and Management for Energy Reduction. Available: http://dimmer.polito.it/

[4] EPBD. (2014). Towards 2020 - Nearly Zero Energy Buildings. Available: http://www.epbd-ca.eu/themes/nearly-zero-energy

[5] MESMERISE-CCS. (2014). MESMERISE-CCS: Multi-Scale Energy Systems Modelling Encompassing Renewable, Intermittent, Stored Energy And Carbon Capture And Storage Available: https://ukccsrc.ac.uk/resources/ccs-projects-directory/multi-scaleenergy-systems-modelling-encompassing-renewable

[6] SHINE-ZC. (2011). SHINE-ZC: Sustainable Housing Innovation Network of Excellence - Zero Carbon. Available: http://gtr.rcuk.ac.uk/project/DB712AB2-B58A-4947-AB0CC890F2BB1BCB

[7] ZenN. (2013). ZenN : Zero Energy Building Renovation. Available: http://www.Zenn-fp7.eu/

[8] EU. (2010). Directive 2010/31/EU of the European Parliament and of the Council of 19 May 2010 on the energy performance of building. Available: $\quad$ http://eur-lex.europa.eu/legalcontent/EN/TXT/HTML/?uri=CELEX:32010L0031\&from=EN

[9] U. S. L. Database. (2008). Climate Change Act 2008. Available: http://www.legislation.gov.uk/ukpga/2008/27

[10] F. Gonzalez-Longatt;, B. S. Rajpurohit;, and S. N. S. ;, "Smart MultiTerminal DC micro-grids for Autonomous Zero-Net Energy Buildings: Implicit Concepts " presented at the EEE PES Innovative Smart Grid Technologies 2015 Asia, ISGT Asia 2015, Bangkok, Thailand, 2015.
[11] B. S. R. K. Chauhan, R. E. Hebner, S. N. Singh, F. Gonzalez-Longatt, "Voltage Standardization of DC Distribution System for Residential Buildings," Journal of Clean Energy Technologies, vol. 4, pp. 167-172, 2016.

[12] G. Pandey, S. N. Singh, B. S. Rajpurohit, and F. M. Gonzalez-Longatt, "Smart DC Grid for Autonomous Zero Net Electric Energy of Cluster of Buildings," IFAC-PapersOnLine, vol. 48, pp. 108-113, // 2015.

[13] I. Richardson;, M. Thomson;, and D. Infield, "A high-resolution domestic building occupancy model for energy demand simulations," Energy and Buildings, vol. 40, pp. 1560-1566, 2008.

[14] I. Richardson, M. Thomson, D. Infield, and C. Clifford, "Domestic electricity use: A high-resolution energy demand model," Energy and Buildings, vol. 42, pp. 1878-1887, 10// 2010.

[15] I. Richardson, M. Thomson, D. Infield, and A. Delahunty, "Domestic lighting: A high-resolution energy demand model," Energy and Buildings, vol. 41, pp. 781-789, 7// 2009.

[16] I. Richardson and M. Thomson, "Integrated simulation of photovoltaic micro-generation and domestic electricity demand: a one-minute resolution open-source model," Proceedings of the Institution of Mechanical Engineers, Part A: Journal of Power and Energy, vol. 127, pp. 73-81, 2012.

[17] B. Haurwitz, "INSOLATION IN RELATION TO CLOUDINESS AND CLOUD DENSITY," Journal of Meteorology, vol. 2, pp. 154-166, 1945/09/01 1945 .

[18] R. T. Pinto, P. Bauer, S. F. Rodrigues, E. J. Wiggelinkhuizen, J. Pierik, and B. Ferreira, "A Novel Distributed Direct-Voltage Control Strategy for Grid Integration of Offshore Wind Energy Systems Through MTDC Network," Industrial Electronics, IEEE Transactions on, vol. 60, pp. 2429-2441, 2013.

[19] F. Gonzalez-Longatt, "Optimal power flow in MTDC systems based on a DC-independent system operator objective," in PowerTech, 2015 IEEE Eindhoven, 2015, pp. 1-6.

[20] F. Gonzalez-Longatt, "Optimal Steady-State Operation of a MTDC system based on DC-Independent System Operator Objectives," in $A C$ and DC Power Transmission, 11th IET International Conference on, 2015, pp. 1-7.

[21] F. Gonzalez-Longatt, "Optimal Power Flow in Multi-terminal HVDC Networks for DC-System Operator: Constant Current Operation," presented at the 50th International Universities Power Engineering Conference (UPEC 2015), Stoke-on-Trent, 2015.

[22] S. A. Soliman and A.-A. H. Mantawy, Modern optimization techniques with applications in electric power systems. New York: Springer, 2012.

[23] M. Aragüés-Peñalba, A. Egea-Àlvarez, O. Gomis-Bellmunt, and A. Sumper, "Optimum voltage control for loss minimization in HVDC multi-terminal transmission systems for large offshore wind farms," Electric Power Systems Research, vol. 89, pp. 54-63, 8// 2012.

[24] F. Gonzalez-Longatt, C. Carmona-Delgado, J. Riquelme, M. Burgos, and J. L. Rueda, "Risk-based DC security assessment for future DCindependent system operator," in Energy Economics and Environment (ICEEE), 2015 International Conference on, 2015, pp. 1-8. 